\title{
Mechanical and In-vitro Performance of CNT Reinforced Hydroxyapatite Prepared by a Shear Mixing Method
}

\author{
Susmita Mukherjee ${ }^{1 *}$, Swarnendu Sen ${ }^{2}$ and Abhijit Chanda ${ }^{3}$ \\ ${ }^{1}$ School of Materials Science and Nanotechnology, Jadavpur University, Kolkata 700032, India \\ ${ }^{2}$ Department of Mechanical Engineering, Jadavpur University, Kolkata 700032, India \\ ${ }^{3}$ School of Bioscience and Engineering, Jadavpur University, Kolkata 700032, India
}

\begin{abstract}
Lack of osteoinductivity and the problem of inherent brittleness are the two major challenges associated with hydroxyapatite (HAp), the main mineral component of bone. This imposes a limitation in its application as a load bearing orthopaedic implant material. The present work aims to overcome the problem of inherent brittleness of HAp by incorporating Carbon Nanotube (CNT) in the HAp matrix. A simple and cost effective shear mixing method was used to mix the CNT and the HAp in optimal proportion to develop the Hap-CNT nanocomposite. The composite was characterised using XRD, FTIR, HRTEM and FESEM techniques. Crystallinity of the composites was well above 99\% with XRD clearly showing characteristics peaks of HAp. HRTEM of the sintered products showed flake like structure while FESEM showed fine microstructure of HAp with sporadic presence of CNT. It is observed that the nanocomposites possess improved fracture toughness with respect to that of pure HAp, which appears to be a great promise for bone tissue engineering. In-vitro studies of the samples, performed in Simulated Body Fluid (SBF) showed widespread growth of apatite crystals on the sample surface.
\end{abstract}

Keywords: Hydroxyapatite; Carbon nanotube; Nanocomposite; Crystal grains; Crystallinity; Microstructure

Abbreviations: Hap: Hydroxyapatite; CNT: Carbon Nanotube; FTIR: Fourier Transform Infrared Spectroscopy; FESEM: Field Emission Scanning Electron Microscopy; MPa: Mega Pascal; SBF: Simulated Body Fluid; mA: Milli Ampere; KV: KiloVolts

\section{Introduction}

Predominance of bone related diseases like osteoporosis, osteoarthritis, etc. have increased the need for bone repair and other bone reconstruction applications, worldwide. Different limitations of using autografts and allografts have led to the huge demand for synthetic biomaterials. Collagen fibre and hydroxyapatite minerals constitute bone, a reinforced hybrid material. HAp, the main mineral component of bone and dentin, possess excellent biocompatibility, osteoconductivity and bone-bonding property and thus has been the primary choice for bone grafts [1]. However, poor mechanical property of bare HAp restricts its use as a major load bearing material and it is extensively used as a coating material on different implant materials such as steel, titanium and titanium alloys [2-4]. Bare HAp has been reported to have low toughness (0.8-1.2 $\left.\mathrm{MPa}^{\mathrm{m}}{ }^{1 / 2}\right)$ and poor flexural strength $(<140 \mathrm{MPa})$ as compared to human bone. Norman et al. [5] measured the fracture toughness of human bone, corrected for size, using bovine bone and showed that it ranges from $4.7 \mathrm{MNm}^{-3 / 2}$ at the age of 25 years to approximately $2.1 \mathrm{MNm}^{-3 / 2}$ at the age of 90 years [5]. To improve the mechanical properties of bare HAp, without sacrificing its biological activities, different reinforcing phases like Zirconia [6-8], glass [9,10], silver [11,12], carbon fiber [13], as well as HAp whiskers [14], Alumina $\left(\mathrm{Al}_{2} \mathrm{O}_{3}\right)$ [15] have been used. Some advanced processing techniques e.g., microwave sintering $[16,17]$, high pressure sintering, etc. are also being tried in recent times. Reports are there where functionalised CNT has been used as the reinforcing material to improve the mechanical properties of HAp [18-20].

Carbon Nanotube is known to be one of the strongest and stiffest materials available and has the potential to improve the strength and toughness of HAp, without sacrificing its bioactivity [21]. CNT consists of rolled-up graphene sheets with hemispherical, half- fullerene endcaps. Multiwalled Nanotubes (MWNT) consist of many concentric graphene sheets, with an interlayer distance of about 0.34 $\mathrm{nm}$, held together by van der Waals bonding and a length varying from several hundred nanometers to several micrometers. Extremely small dimension and high aspect ratio results in the remarkable tensile strength, high resilience, flexibility and other unique properties of $\mathrm{CNT}$. Inclusion of CNT in the ceramic matrix is expected to improve the toughness as well as the stiffness of the composite with respect to the pure ceramic phase. Ruoff inferred that when CNT is used in the composite, fracture occurs via collapse of the inner walls of CNT, thereby providing extra absorption energy and increased toughness of the composite [22].

In the recent past, a number of studies have focused on the issue of functionalisation of CNT to promote good interlinking with the matrix. But the process of functionalisation is often found to be very tricky and requires a lot of technical precision. A slight variation in the concentration of the functionalising agent completely oxidises the CNT, thereby jeopardising the formation of the composite.

With this backdrop, the current work proposes a simple shear mixing technique, (avoiding experimental complications associated with functionalisation of CNT) to develop CNT-HAp composite that would give improved mechanical properties. Various compositions of CNT-HAp composites have been developed by adding 0.5-2 weight percentage of CNT in laboratory synthesized HAp. Attempts have been made to quantify the extent of enhancement in mechanical properties

*Corresponding author: Susmita Mukherjee, School of Materials Science and Nanotechnology, Jadavpur University, Kolkata 700032, India, Tel: 91 9674459006; E-mail: susm08@gmail.com

Received February 19, 2013; Accepted March 25, 2013; Published March 29 2013

Citation: Mukherjee S, Sen S, Chanda A (2013) Mechanical and In-vitro Performance of CNT Reinforced Hydroxyapatite Prepared by a Shear Mixing Method. J Nanomed Nanotechol 4: 169. doi:10.4172/2157-7439.1000169

Copyright: (c) 2013 Mukherjee S, et al. This is an open-access article distributed under the terms of the Creative Commons Attribution License, which permits unrestricted use, distribution, and reproduction in any medium, provided the original author and source are credited. 
due to the addition of CNT in various proportions so as to identify the best suitable one.

\section{Material and Methods}

\section{Materials}

Powdered HAp $\left[\mathrm{Ca}_{10}\left(\mathrm{PO}_{4}\right)_{6}(\mathrm{OH})_{2}\right]$ was synthesized in the laboratory using A.R grade Ortho-Phosphoric Acid, $\mathrm{H}_{3} \mathrm{PO}_{4}$ (S.D. FineChem Ltd., India, $85 \%$ pure) and Calcium Hydroxide, $\mathrm{Ca}(\mathrm{OH})_{2}$ (S.D. Fine-Chem Ltd., India, 95\% pure). Multiwalled Carbon Nanotube (MWCNT, $>95 \%$ purity) with a diameter of $10-30 \mathrm{~nm}$ and an average length of 1-10 $\mu \mathrm{m}$ was procured from Nanoshel LLC, USA.

\section{Synthesis of HAp and HAp-CNT composite}

Powdered HAp was synthesized in the laboratory following the wet chemical method [23], using $\mathrm{H}_{3} \mathrm{PO}_{4}$ and $\mathrm{Ca}(\mathrm{OH})_{2}$ as starting reagents. $\mathrm{H}_{3} \mathrm{PO}_{4}$ solution was added dropwise in the $\mathrm{Ca}(\mathrm{OH})_{2}$ solution and the molar concentration was adjusted to have a theoretical $\mathrm{Ca} / \mathrm{P}$ ratio of 1.66. The solution was aged for $24 \mathrm{hrs}$ and then filtered. The white precipitate was repeatedly washed with double distilled water, dried at $60-70^{\circ} \mathrm{C}$ and finally calcined at $800^{\circ} \mathrm{C}$ for $2 \mathrm{hrs}$. Weighed amounts of calcined HAp and the purified CNT powders were mixed together in a high energy planetary ball mill (Fritsche Pulverissette 5, Germany), using acetone as the medium. The milling was done in two stages, at $500 \mathrm{rpm}$ for first $2 \mathrm{hrs}$ and then at $300 \mathrm{rpm}$ for next $5 \mathrm{hrs}$. For milling, rust free steel balls with good metallic polish and diameter of about 5 mm were used, maintaining a 10:1 ratio of weight of balls to the weight of powder used. To avoid contamination, prior to the milling, the steel balls and the milling pots were thoroughly cleansed with Alcohol, and then with Acetone. Average particle size of the milled powders were consistently less than $100 \mathrm{~nm}$.

The milled powders were sieved and subsequently uni-axially pressed at $150 \mathrm{MPa}$ for 2 mins at room temperature to obtain an average of $40-50 \%$ green density. To prevent non-uniform compaction along the length and the walls of the samples, thin pellets were prepared. The typical size of the pellets were $1.2 \mathrm{~cm} \times 0.4 \mathrm{~cm}$ (diameter $\times$ thickness). The sintering was carried out in two steps, first upto $700^{\circ} \mathrm{C}$ at a heating rate of $3^{\circ} \mathrm{C} / \mathrm{min}$ and then upto $1250^{\circ} \mathrm{C}$ at a heating rate of $6^{\circ} \mathrm{C} / \mathrm{min}$, under Argon atmosphere. A dwell time of $1 \mathrm{hr}$ was allowed, followed by furnace cooling. The sintered samples were used for different characterizations. Three different compositions of the HAp-CNT composite with respect to weight of CNT: $0.5 \%, 1 \%$ and $2 \%$ were prepared.

\section{Preparation of SBF solution}

Simulated body fluid (SBF) was prepared in the laboratory according to the procedure developed by Kokubo et al. [24]. Appropriate quantities of reagents $\mathrm{NaCl}, \mathrm{NaHCO}_{3}, \mathrm{KCl}, \mathrm{K}_{2} \mathrm{HPO}_{4} .3 \mathrm{H}_{2} \mathrm{O}$, $\mathrm{MgCl}_{2} \cdot 6 \mathrm{H}_{2} \mathrm{O}, \mathrm{CaCl}_{2}, \mathrm{Na}_{2} \mathrm{SO}_{4}$ and tris buffer were dissolved in $1 \mathrm{~L}$ of deionised water so as to have an ionic concentration similar to that of the human blood plasma. Table 1 shows the ionic concentration of the SBF as developed by Kokubo et al. [24], its comparison with human blood plasma and amount of the reagents added. The reagents were added with constant stirring to ensure complete dissolution. The $\mathrm{pH}$ of the solution was adjusted to 7.4 using dilute $\mathrm{HCl}$ at $37^{\circ} \mathrm{C}$.

\section{Characterisation}

X-ray Diffraction (XRD) analysis was done to study the phases and the relative percentage of crystallisation using a X-ray diffractometer (Rigaku, Ultima III) operating at $30 \mathrm{kV}$ and $20 \mathrm{~mA}$ with $\mathrm{CuK}$ radiation,

\begin{tabular}{|c|c|c|}
\hline lonic concentration $\mathbf{( m m o l} / \mathbf{d m} 3)$ & SBF & Blood plasma \\
\hline $\mathrm{Na}^{+}$ & 142.0 & 142.0 \\
\hline $\mathrm{K}^{+}$ & 5.0 & 5.0 \\
\hline $\mathrm{Mg}^{+}$ & 1.5 & 1.5 \\
\hline $\mathrm{Ca}^{+}$ & 2.5 & 2.5 \\
\hline $\mathrm{Cl}^{-}$ & 147.8 & 103.0 \\
\hline $\mathrm{HCO}^{-}$ & 4.2 & 27.0 \\
\hline $\mathrm{HPO}^{-}$ & 1.0 & 1.0 \\
\hline $\mathrm{SO}^{-}$ & 0.5 & 0.5 \\
\hline
\end{tabular}

Table 1: Ion concentrations $\left(\mathrm{mmol} / \mathrm{dm}^{3}\right)$ of SBF and human blood plasma.

$\lambda=0.15418 \mathrm{~nm}$. The relative crystallisation percentage was measured by using equation 1 ,

$$
\mathrm{X}_{\mathrm{C}}=\left(1-\frac{\mathrm{V}_{112 / 300}}{\mathrm{I}_{300}}\right)
$$

where $\mathrm{I}_{300}$ is the intensity of the HAp peak at (300) surface and $\mathrm{V}_{112 / 300}$ is the intensity of the valley between the peaks at (300) and (112) surfaces [25]. The Fourier Transform Infrared (FTIR) spectra were recorded on a Schimadzu spectrophotometer (IR Prestige 21, 200VCE) in the region between 400 and $4500 \mathrm{~cm}^{-1}$ at room temperature to study the bonds present in the molecules. Bulk densities as well as shrinkage of the green and the sintered samples were calculated, by simple gravimetric analysis to study the extent of compaction.

The morphological and microstructural details of the composites were studied using Field Emission Scanning Electron Microscope (FESEM, Hitachi, S4800) and High Resolution Transmission Electron Microscope (HRTEM, JEOL, JEM 2100).

The sintered samples were mirror polished using an automated polishing machine (LECO, Spectrum System 1000) and the surface roughness was measured in a Profilometer (Talysurf plus Surtonic 3P, England). Average surface roughness obtained were a Centre Lined Average $(\mathrm{Ra})$ value of less than $0.1 \mu \mathrm{m}$. Hardness and Fracture Toughness $\left(\mathrm{K}_{1 \mathrm{c}}\right)$ of the polished samples were evaluated using an automated Vickers Hardness testing machine (LECO, LV-700AT, MI). Four different loads of $0.3 \mathrm{kgf}, 1 \mathrm{kgf}, 3 \mathrm{kgf}$ and $5 \mathrm{kgf}$ were applied, with a holding time of 10 secs. A minimum of six measurements were conducted on each sample. The average of these readings were computed, reported and compared. Fracture toughness, $\mathrm{K}_{\mathrm{IC}}$ was calculated using the equation for Radial Median Crack system [26,27].

$$
\mathrm{K}_{\mathrm{IC}}=0.016(\mathrm{E} / \mathrm{H})^{0.5}\left(\mathrm{P} / \mathrm{C}^{1.5}\right)
$$

Where $\mathrm{P}$ denotes the indentation load, $\mathrm{E}$ denotes Young's modulus, $\mathrm{H}$ denotes the Vickers hardness, $\mathrm{C}$ is half of the radial crack length, $\mathrm{C}$ is average crack length and a is the average crack diagonal. The crack length was measured and confirmed that the ratio of crack length to half the diagonal exceeds 2.5 , the pre-requisite for assuming radial median crack geometry.

The mirror polished disc samples were used for the nanoindentation tests using a Vickers Nanoindentor (H100, Fischer, Germany). The indentation load was varied from $10 \mathrm{mN}$ to $10 \mathrm{~N}$ to see whether there was any indentation size effect for these composite materials. A maximum indentation depth of $100 \mathrm{~nm}$ was allowed with a dwell time of 10 secs for each indentation and the distance between two indentation was kept at least $200-300 \mu \mathrm{m}$ to avoid any stress strain influence caused by the adjacent indentation. Loading and unloading curves were recorded from the micro-indentation studies using the inbuilt data acquisition software. The hardness and elastic modulus were calculated on the basis of the standard procedure using the Oliver and Pharr [27] method. 
To assess the bioactivity of the HAp-CNT composites in-vitro, disc samples were kept immersed in the SBF solution and the apatite formation was studied. A set of two samples of each composition were immersed in $15 \mathrm{ml}$ of freshly prepared SBF solution, under static condition in a incubator at $37^{\circ} \mathrm{C}$ for 4 weeks. To avoid saturation, the SBF was changed after every 3 days. At the end of $2^{\text {nd }}$ and $4^{\text {th }}$ week, the samples were taken out, dried at $65^{\circ} \mathrm{C}$ and the weights taken. The dried samples were also tested in a Vickers Hardness tester to study the effect of bioresorption on the mechanical property, if any. The surface microstructure were also observed using SEM technique.

\section{Results and Discussions}

\section{Density and shrinkage study}

The bulk density as well as the shrinkage of the green and the sintered samples was calculated, using Archimedes principle. Figures $1 \mathrm{~A}$ and $1 \mathrm{~B}$ shows the plot of the green and sintered density and that of linear and volume shrinkage respectively. Figure 1A shows that bulk HAp has poor green as well as sintered density. The $1 \%$ and $2 \%$ composite shows higher green and sintered density than that of pure HAp. Figure 1B shows that HAp exhibits a higher shrinkage compared to that of the HAp-CNT composites. The percentage theoretical density, $\rho_{\text {th }}$ (theoretical density of HAp is $3.16 \mathrm{~g} / \mathrm{cc}$ ) of the samples show that the composites have achieved more than $90 \%$ of theoretical density on sintering.

\section{XRD analysis}

Figure 2(A) shows the XRD spectra of bare HAp as well as the Hap-CNT composites. It is found that the d values matches with that of stoichiometric HAp (JCPDS No.09-432) and no new peaks are obtained. Pure CNT, shown in inset, gives a characteristic peak at $26^{\circ}$, which is also present in pure HAp spectra. It is seen that in the spectra of the HAp-CNT composites, the peak at $26^{\circ}$ get sharpened, confirming the presence of CNT in the composites. Thus it may be concluded that the composites are phase pure and inclusion of CNT does not alter the phase of the hydroxyapatite. Degrees of crystallinity (XC) of the samples were determined from the XRD spectra. It is seen that the crystallinity increases with increase in CNT content, as shown in table 2. Pure HAp has about $95 \%$ crystallinity, while the composites have an average crystallinity of greater than $99 \%$.

\section{FTIR study}

FTIR spectra of the pure HAp and the HAp-CNT composites
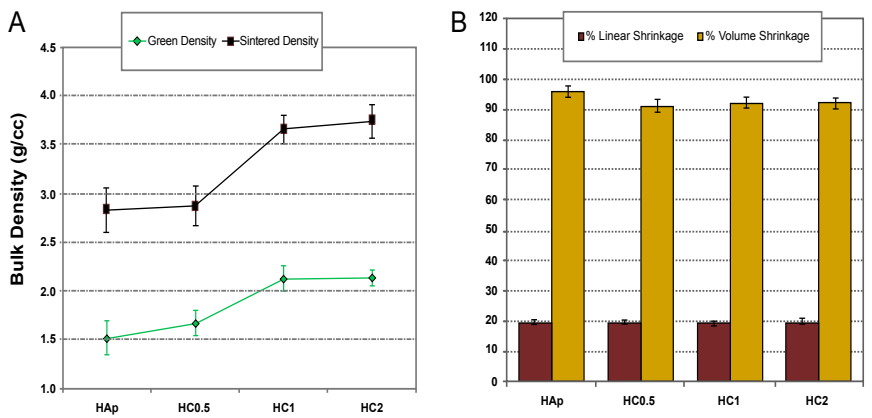

Figure 1: (A) Green density vs sintered density of HAp and HAp-CNT composites; (B) Linear shrinkage vs volume shrinkage of HAp and HAp-CNT composites.
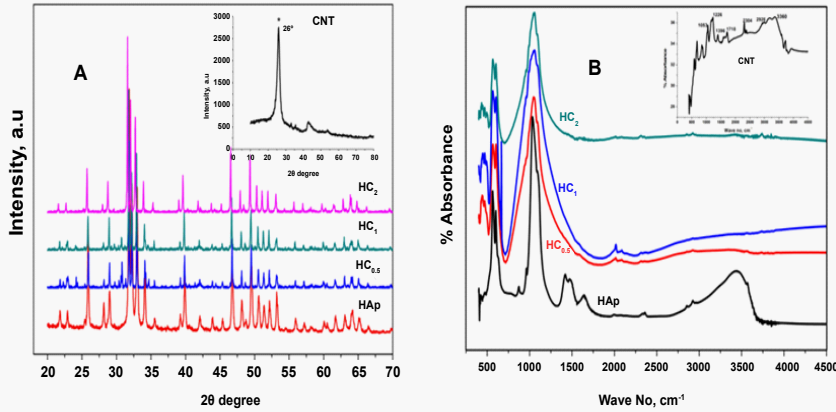

Figure 2: (A) XRD patterns of HAp and HAp-CNT composites with pure CNT given in inset; (B) FTIR spectra of HAp and HAp-CNT composites with pure CNT given in inset.

\begin{tabular}{|c|c|c|}
\hline Samples & Composition & \% Crystallinity \\
\hline $\mathrm{HAp}$ & Pure HAp & 95.8 \\
\hline $\mathrm{HC}_{0.5}$ & $\mathrm{HAp}+0.5 \% \mathrm{CNT}$ & 99.64 \\
\hline $\mathrm{HC}_{1}$ & $\mathrm{HAp}+1 \% \mathrm{CNT}$ & 99.8 \\
\hline $\mathrm{HC}_{2}$ & $\mathrm{HAp}+2 \% \mathrm{CNT}$ & 99.3 \\
\hline
\end{tabular}

Table 2: Crystallinity of HAp-CNT composites.

are shown in figure 2(B), with that of bare CNT being shown in the inset. The spectrum of bare CNT shows characteristic peaks at 1053, $1226,1396,1718,2304,2926,3375$ and $3722 \mathrm{~cm}^{-1}$ which is attributed to the $\mathrm{C}=\mathrm{O}$ groups $\left(1099\right.$ and $\left.1718 \mathrm{~cm}^{-1}\right)$, asymmetric and symmetric stretching of $\mathrm{C}-\mathrm{H}$ bonds $\left(2304\right.$ and $2926 \mathrm{~cm}^{-1}$ ) and the $\mathrm{OH}$ group (3375 and $3722 \mathrm{~cm}^{-1}$ ) resulting from the chemical treatment during the purification process of the CNT powder. The spectrum of pure HAp shows peaks at 565, 603, 1045, 1089, 1415 (phosphate, PO4 group), 1643 and $3445 \mathrm{~cm}^{-1}$ (hydroxyl group, $\mathrm{OH}$ ). The HAp-CNT composites show XRD peaks similar to that of bare HAp, except for those of hydroxyl group $(-\mathrm{OH})$, which is due to the loss of the extra moisture during the sintering process. Moreover, no new peaks are observed which implies that no new bonds are being formed in the composites and the bonding between HAp and CNT is purely physical. The presence of CNT in the composites does not change the basic structure of HAp.

\section{Microstructure analysis}

The Scanning Electron Microscopy (SEM) was carried out to study the surface morphology and the microstructure of the samples. The SEM images of the HAp-CNT composites are shown in figure 3. It is seen from the images that the composites have a porous microstructure and consist of interconnected grains, which is highly desirable for cellular growth. Figures $4 \mathrm{~A}$ and $4 \mathrm{~B}$ show the FESEM images of bare HAp and the HAp-CNT composites. From the images, it may be concluded that the microstructure of the composites is different from that of bare HAp or pure CNT. It is also observed that the evolved nanostructures have a grain-diameter of 600-800 nm.With increase in CNT concentration, the apparent porosity of the samples increases. Figures $4 \mathrm{C}$ and $4 \mathrm{D}$ show that at higher CNT concentration, hair like CNT structures are attached to the HAp grains. The inset picture of figure 4D shows the microstructure of the $2 \%$ composite at a higher magnification which reveals nanofibre like structures of 20-30 nm diameter.

To further understand the morphology, the microstructures of HAp, CNT and HAp-CNT composites were investigated by HRTEM. Figure 5(A) exhibits rod like CNT structures with an average diameter of 20-50 $\mathrm{nm}$ and an average length of $600-800 \mathrm{~nm}$. The interlamellar distance of the walls of the CNT has been calculated to be approx 0.317 
Citation: Mukherjee S, Sen S, Chanda A (2013) Mechanical and In-vitro Performance of CNT Reinforced Hydroxyapatite Prepared by a Shear Mixing Method. J Nanomed Nanotechol 4: 169. doi:10.4172/2157-7439.1000169

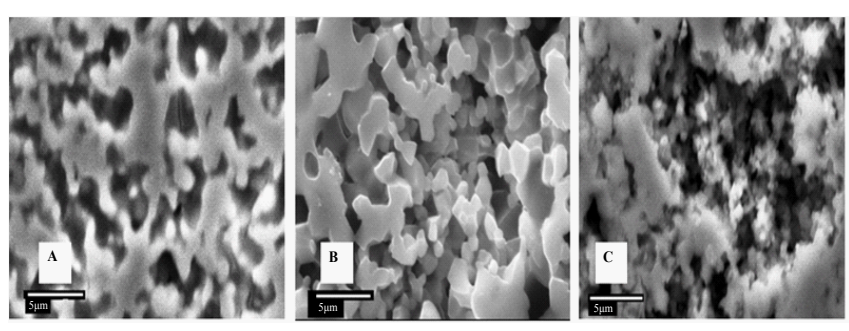

Figure 3: SEM images of HAp-CNT composites: (A) pure Hap; (B) $\mathrm{HC}_{1}$; (C) $\mathrm{HC}_{2}$.

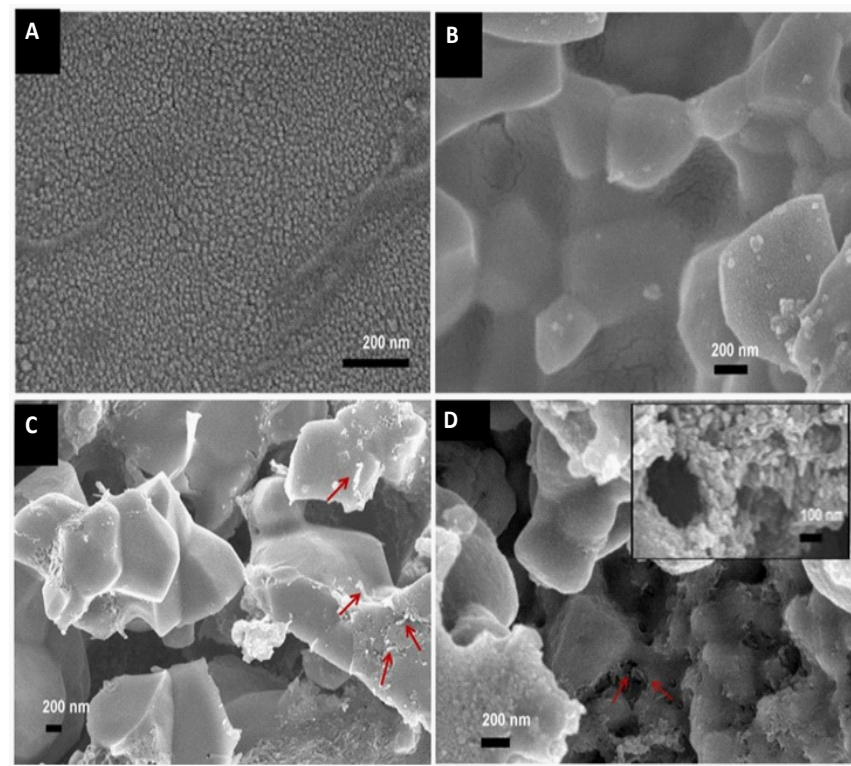

Figure 4: FESEM images of: (A) bare HAp; (B) $0.5 \%$ HAp-CNT; (C) $1 \% \mathrm{HAp}$ CNT; (D) 2\% HAp-CNT composite.

$\mathrm{nm}$, as shown in figure 5(B). Figure 5(C) shows the regular shaped HAp particles, with an average size of $100-150 \mathrm{~nm}$, with the lattice planes being shown in the inset. Figures 5D and 5E shows the microstructure of HAp-CNT composites before sintering which shows distinct HAp particles attached to the tube like CNT structures. But on sintering, a two dimensional flake like structure was obtained (Figure 5F) where individual HAp particles and CNT structures cannot be identified and multilayered HAp crystals appear to be deposited on the CNT structures.

\section{Mechanical properties}

As far as the mechanical properties are concerned, the most important challenge is to increase the toughness of bare HAp without sacrificing the two vital mechanical properties, namely the hardness and stiffness as well as the bioactivity of the material. In the present work, a series of studies have been performed both with the macro and the micro indentation, to find out the aggregate behavior as well as to understand the effect of localized heterogeneity.

Figure 6 shows the plot of hardness (HV) and fracture toughness $\left(\mathrm{K}_{1 \mathrm{C}}\right)$ of the composite samples. It is seen that the hardness of the $0.5 \%$ composite $\left(\mathrm{HC}_{0.5}\right)$ is almost similar to that of bare HAp and subsequently decreases for the $1 \%\left(\mathrm{HC}_{1}\right)$ and $2 \%\left(\mathrm{HC}_{2}\right)$ composite. It is also seen that $\mathrm{HC}_{1}$ gives a maximum Fracture Toughness of about 1.9 (about 120\% increases over bare HAp). The other compositions show $\mathrm{K}_{1 \mathrm{C}}$ values close to that of bare HAp.

The Young's modulus results of the HAp-CNT composites were obtained from the nanoindentation experiment. Figure 7 shows that under a load of $100 \mathrm{mN}$, the $0.5 \%$ composite $\left(\mathrm{HC}_{0.5}\right)$ possesses a higher Young's modulus than that of bare HAp, while it decreases with the $1 \%$ $\left(\mathrm{HC}_{1}\right)$ and $2 \%\left(\mathrm{HC}_{2}\right)$ composites. At this juncture, it may be noted that to avoid stress shielding, it is often required to develop HAp with lower stiffness. In both $1 \%$ and $2 \%$, CNT doped HAp, lower values of stiffness were achieved, and however the extent of change was not that high.

The hardness and the Young's modulus values are found to be more or less similar. The difference in hardness and the stiffness values are well within the experimental scatter. To find out the toughness, four different indentation loads were selected. Indentation cracks were

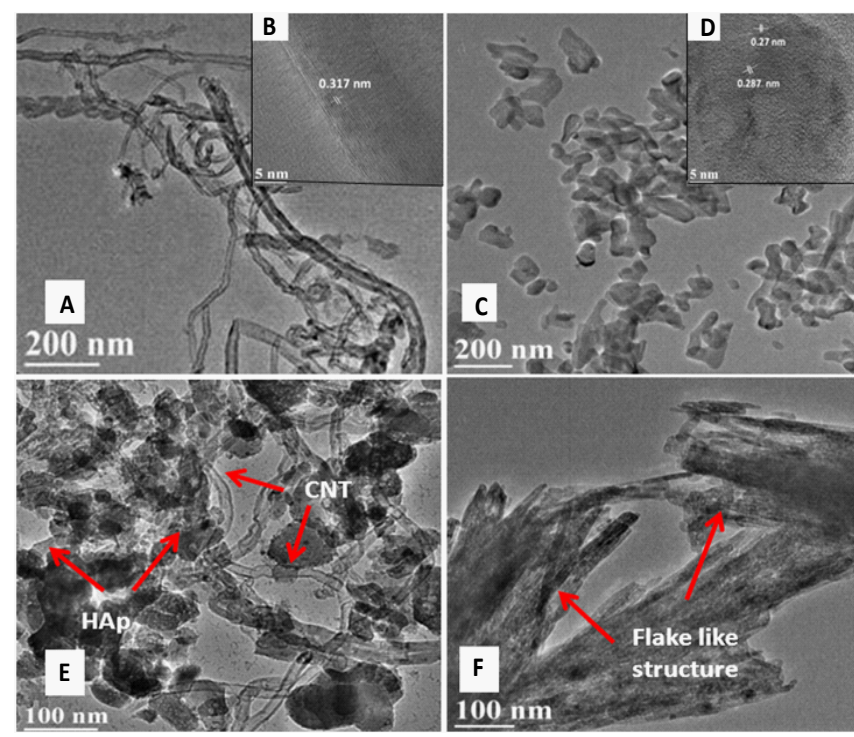

Figure 5: HRTEM images of HAp-CNT showing: (A) pure CNT; (B) interlamellar distance of CNT; (C) Pure HAp particulates; (D) lattice of Hap (E) HAp-CNT powders, before sintering; (F) HAp-CNT composite, after sintering.

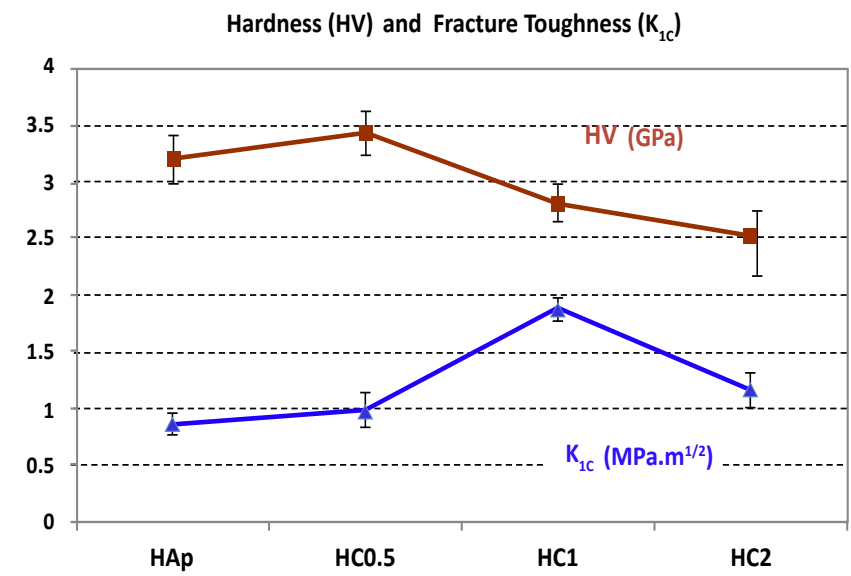

Figure 6: Hardness and fracture toughness of HAp-CNT composites. 
measured and found to be predominantly radial or median in nature. A majority of indentation cracks showed c/a ratio greater than 2.5. In few cases, particularly with lower loads, indentation cracks were Palmqvist in nature. In both radial/median cracks and Palmqvist cracks, toughness values were found to be around 1.8-2.0 for HApCNT composite in contrast with 0.8-0.9 for pure HAp. It shows that incorporation of CNT in the HAp matrix in optimal proportion ( $1 \%$ by weight) makes a twofold increase in toughness. It can be attributed to the energy absorption by MWCNT for the collapse of the concentric C-layers when subjected to external stress [22]. This energy absorption mechanism helps in dissipating the energy which in turn increases the toughness. Fracture toughness of human bone is about 2-4 MPa.m ${ }^{1 / 2}$, depending on the age of the person and with $1 \%$ CNT composite we can achieve a toughness close to that of human bone.

\section{Bioresorption study}

Exposure to SBF clearly shows that both pure HAp and HAp-CNT composites promote good apatite formation on the sample surface, as observed from the SEM profilometry (Figure 8). In fact a careful observation shows that the apatite formation is slightly better in case of the composites than in case of pure HAp. This can be confirmed by

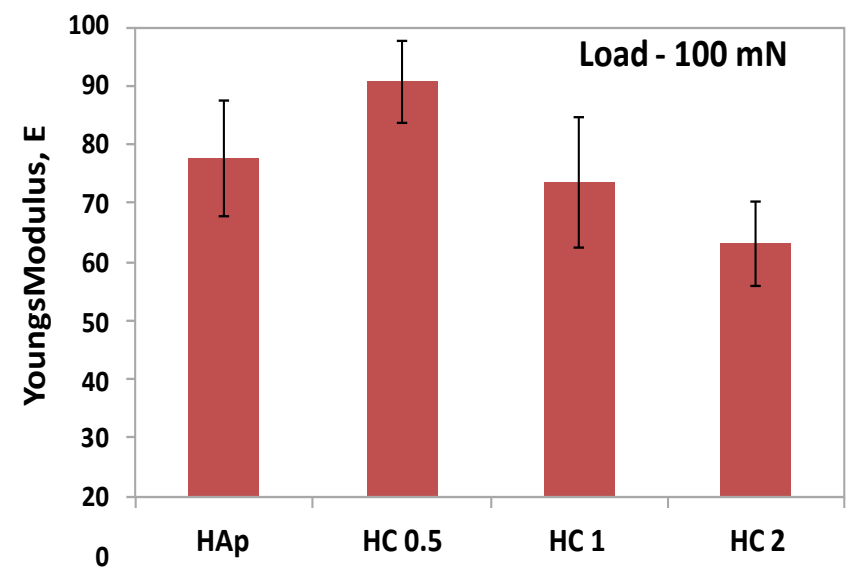

Figure 7: Young's Modulus results of the HAp-CNT composites under a load of $100 \mathrm{mN}$.

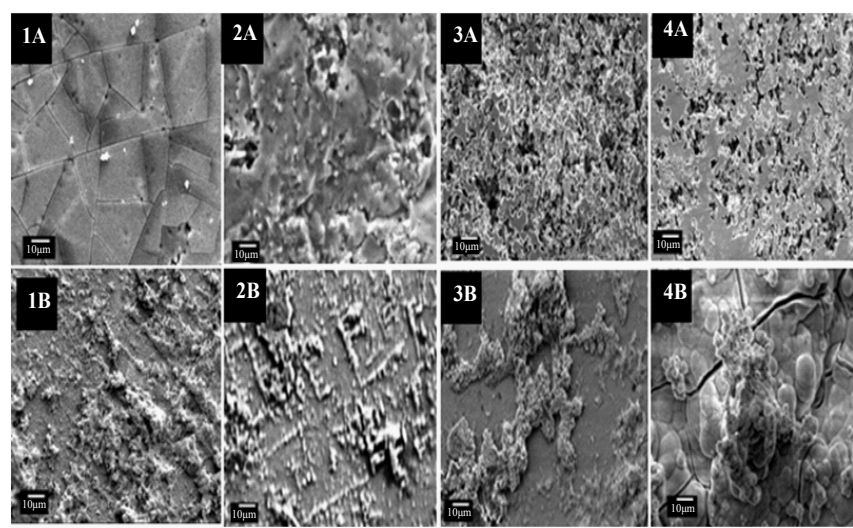

Figure 8: Photos showing apatite deposition on samples at $(A) 0^{\text {th }}$ week and (B) $4^{\text {th }}$ week of $1: \mathrm{HAp}, 2: 0.5 \%$ composite, $3: 1 \%$ composite, $4: 2 \%$ composite.

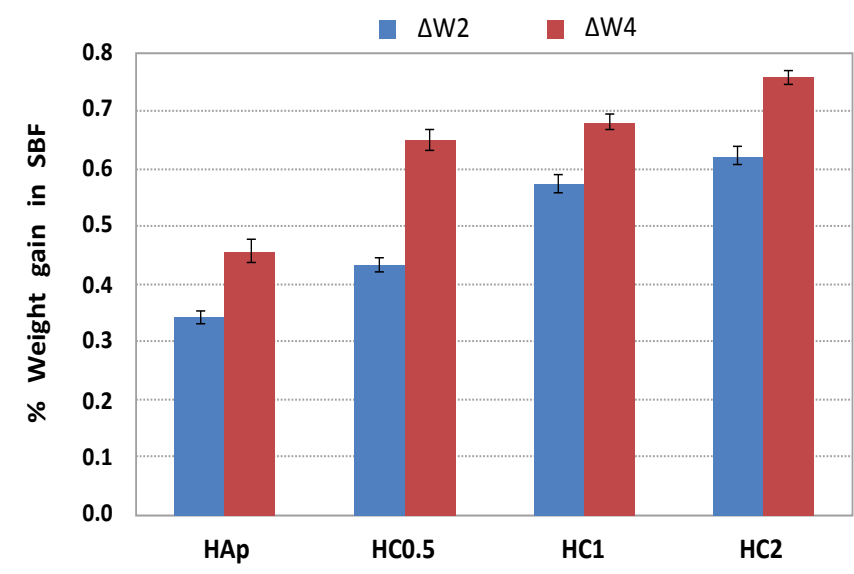

Figure 9: Apatite deposition on the samples at $0^{\text {th }}$ week and $4^{\text {th }}$ week of HAp, $\mathrm{HC}_{0.5}, \mathrm{HC}_{1}$ and $\mathrm{HC}_{2}$.

studying the weight gain of the samples, both after the $2^{\text {nd }}$ and the $4^{\text {th }}$ week (Figure 9) of SBF exposure. The SEM images (Figure 8) shows that the apatite formation occurs in layers and also quite uniformly across the whole surface. Such uniform and systematic growth of apatite over time clearly indicates the primary signs of osteoconductivity of the composites. Estimation of hardness of the samples shows that there is almost no loss in the strengths of the samples after soaking in SBF for about 4 weeks. However, this is only preliminary evidence. It requires a detailed in-vivo study and animal trial study before making any major conclusion.

\section{Conclusion}

From the above discussion, it may be concluded that HAp can be reinforced with CNT with a simple shear mixing technique. It has been observed that in CNT-HAp composite, a flake like structure is formed after sintering while before sintering HAp particles were found to adhere loosely to CNT. The composite showed good mechanical and physical properties. The $1 \%$ CNT-HAp composite showed marked improvement in toughness ( $120 \%$ increases) without compromising hardness and stiffness. This composition also had substantially high apatite formation when exposed to SBF and it has good potential as a new biomaterial for future.

\section{Acknowledgement}

Authors would like to acknowledge the kind cooperation and help provided by Dr. Probal Das and Mr. Biswanath Kundu of Central Glass and Ceramic Research Institute, Kolkata. We would also like to thank Mr. Ajoy Kumar Prodhan, Department of Chemical Engineering, Jadavpur University. One of the authors (SM) would like to acknowledge CSIR for providing the fellowship and financial assistance to carry out the work.

\section{References}

1. Hench LL, Wilson J (1993) An Introduction to bioceramics. (1stedn), World Scientific, Singapore.

2. Best SM, Sim B, Kayser M, Downes S (1997) The dependence of osteoblastic response on variations in the chemical composition and physical properties of hydroxyapatite. J Mater Sci Mater Med 8: 97-103.

3. Nasca RJ, Lemons JE, Deinlein DA (1989) Synthetic biomaterials for spina fusion. Orthopedics 12: 543-548.

4. Fujibayashi S, Shikata J, Tanaka C, Matsushita M, Nakamura T (2001) Lumbar posterolateral fusion with biphasic calcium phosphate ceramic. J Spinal Disord 14: $214-221$ 
Citation: Mukherjee S, Sen S, Chanda A (2013) Mechanical and In-vitro Performance of CNT Reinforced Hydroxyapatite Prepared by a Shear Mixing Method. J Nanomed Nanotechol 4: 169. doi:10.4172/2157-7439.1000169

5. Norman TL, Vashishth D, Burr DB (1995) Fracture Toughness of Human Bone under Tension. J Biomech 28: 309- 320

6. Habraken W, Wolke JGC, Jansen JA (2007) Ceramic composites as matrices and scaffolds for drug delivery in tissue engineering. Adv Drug Deliv Rev 59: 234-248.

7. Delgado JA, Morejon L, Martınez S, Ginebra MP, Carlsson N, et al. (1999) Zirconia-toughened hydroxyapatite ceramic obtained by wet sintering. J Mater Sci Mater Med 10: 715-719.

8. Shen ZJ, Adolfsson E, Nygren M, Gao L, Kawaoka H, et al. (2001) Dense hydroxyapatite-zirconia ceramic composites with high strength for biological applications. Adv Materials 13: 214-216

9. Bonfield W, Knowles JC (1993) The effect of glass composition on mechanical properties and its relationship to phase change. J Biomed Mater Res 27: 1591 1598.

10. Lopes MA, Monterio FJ, Santos JD (1999) Glass-reinforced hydroxyapatite composites: fracture toughness and hardness dependence on microstructura characteristics. Biomaterials 20: 2085-2090.

11. Chaki TK, Wang PE (1994) Densification and strengthening of silver reinforced hydroxyapatite-matrix composite prepared by sintering. J Mater Sci Mater Med 5: 533-542.

12. Zhang X, Gubbels GHM, Terpstra RA, Metselaar R (1997) Toughening of calcium hydroxyapatite with silver particles. J Mater Sci 32: 235-243.

13. Park K, Vasilos T (1997) Characteristics of carbon fibre-reinforced calcium phosphate composites fabricated by hot pressing. J Mater Sci Lett 16: 985-987.

14. Suchanek W, Yashima M, Kakihana M, Yoshimura M (1997) Hydroxyapatite/ hydroxyapatite-whisker composites without sintering additives: mechanical properties and microstructural evolution. J Am Ceram Soc 80: 2805-2813.

15. Young MK, Kim S, Kim HE (1999) Reinforcement of Hydroxyapatite Bioceramic by Addition of $\mathrm{ZrO} 2$ Coated with $\mathrm{Al}_{2} \mathrm{O}_{3}$. J Am Ceram Soc 82: 2963-2968.
16. Chanda A, Dasgupta S, Bose S, Bandyopadhyay A (2009) Microwave sintering of calcium phosphate ceramics. Mater Sci Eng C 4: 1144-1149.

17. FangY, Roy DM, Cheng J, Roy R, Agrawal DK (1993) Microwave sintering of hydroxyapatite-based composites. Ceram Trans 36: 397-407.

18. Boccaccini AR, Cho J, Subhani T, Kaya C, Kaya F (2008) Electrophoretic deposition of carbon nanotube-reinforced hydroxyapatite. Ceram Int 34: 18431847.

19. Kealley C, Elcombe M ,Riessen A, Ben-Nissan B (2006) Development of carbon nanotube-reinforced hydroxyapatite bioceramics. Physics B 385-386: 496-498.

20. Zhang Y, Tan S, Yin Y (2003) C-fibre reinforced hydroxyapatite bioceramics. Ceram Int 29: 113-116

21. Ashley A, Best SM, Kinloch IA (2007) Hydroxyapatite-Carbon Nanotube composites for biomedical applications: A review. Int J Appl Ceram Tech 4 $1-13$.

22. Ruoff RS, Lorents DC (1995) Mechanical and Thermal Properties of Carbon Nanotubes. Carbon 33: 925-930.

23. Bouyer E, Gitzhofer F, Boulos MI (2000) Morphological Study of Hydroxyapatite Nanocrystal suspension. J Mater Sci Mater Med 11: 523-531.

24. Kokubo T, Kushitani H, Sakka S, Kitsugi T, Yamamuro T (1990) Solutions able to reproduce in vivo surface-structure changes in bioactive glass-ceramic A-W J Biomed Mater Res 24: 721-734.

25. Pang YX, Bao X (2003) Influence of temperature, ripening time and calcinations on the morphology and crystallinity of HA nanoparticles. J Eur Ceram Soc 23 : 1697-1704.

26. Niihara K, Morena R, Hasselman DPH (1981) Evaluation of $K_{1 C}$ of brittle solids by the indentation method with low crack-to-indent ratios. J Mater Sci Lett 1 : $13-16$

27. Oliver WC, Pharr GM (1992) An improved technique for determining hardness and elastic modulus using load and displacement sensing indentation experiments. J Mater Res 7: 1564-1583. 